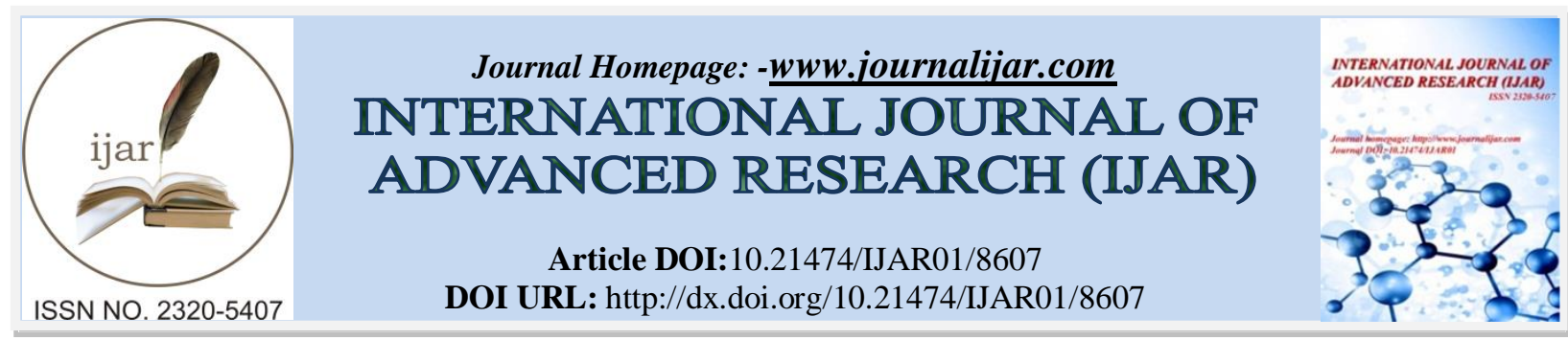

RESEARCH ARTICLE

\title{
MINIMAL INVASIVE RADIOFREQUENCY ABLATION GUIDED BY ULTRASOUND VERSUS SURGICAL EXCISION IN TREATMENT OF BREAST FIBROADENOMAS.
}

\author{
Hassan A. Saad, Ahmed M. El Teliti and Abdelwahab S. Almoregy and Ibrahim A.Heggy. \\ General surgery department, Zagazig University.
}

\section{Manuscript Info}

\section{Manuscript History}

Received: 04 January 2018

Final Accepted: 06 February 2019

Published: March 2019

\section{Abstract}

Introduction:-

Benign breast fibroadenoma is the commonest breast disease among women. treatment for giant (or juvenile) fibroadenomas in adult is necessary because of disfigurement of the breast, potential to cause psychological harmful effect, and potential for enlargement with venous congestion, glandular damage, pressure skin necrosis and ulceration.

Patients and Methods:-

Thirty patients with breast fibroadenomas accepted US guided percutaneous RFA and 30 patients with surgical excision under general or local anesthesia at Zagazig university hospital surgical department.

Results:

RFA has some significant advantages of keeping the shape and skin integrity of the breast as well as for the esthetic effects with small residual mass recurrence but in surgical excision 3 cases had skin disfigurement. in our study no significant skin or muscle burn resulted but only mild edema in 2 patients that disappeared 8 days later. No recurrence in surgical excision in our study observed.

\section{Conclusion:-}

RFA has its significant advantages in treating breast fibroadenoma, especially for multiple fibroadenomas.

Key words:-

Breast fibroadenoma biobsy radiofrequency ablation.

Corresponding Author:-Hassan A. Saad.

Address:-General surgery department, Zagazig University.

Copy Right, IJAR, 2019,. All rights reserved.

\section{Introduction:-}

Benign breast fbroadenoma is the commonest breast disease among women. [1] Although the pathological results are very important, general high frequency ultrasound (US) imaging examination can be used for diagnosis 
confirmation. [2] Studies suggest that non proliferative benign breast lesions with non abnormal proliferative lesions will not develop into malignant changes, but those abnormal proliferative lesions have a high risk for breast cancer disease or malignant changes. [3] Furthermore, treatment for giant (or juvenile) fibroadenomas in adult is necessary because of disfigurement of the breast, potential to cause psychological harmful effect, and potential for enlargement with venous congestion, glandular damage, pressure skin necrosis and ulceration. [4] Therefore, close observation and early intervention must be done for benign breast tumors by periodic examination especially with a family history of breast malignant disease. [5] In recent years, the rapid development of US technology provides new information for treating breast fibroadenomas. [6] High frequency US can accurately measure the size, the shape, the location, the depth, the internal echo and also the blood supply of the breast nodules, and can be used in diagnosis by guiding needle biopsy, and even treatment.[7] Up to now, surgical resection is still the preferred procedure in the treatment of breast fibroadenomas . [8]

Non malignant nature of the lesions is an important factor in treatment of fibroadenomas by minimally invasive techniques with good efficacy, safety and cosmesis. [9] This review will describe minimally invasive RF techniques of breast lesions via percutaneous approaches in comparison to surgical excision.

We discuss the outcomes, advantages and limitations for each.

\section{Patients And Methods:-}

The study done From September 2017 to January 2019, we had 60 females' patients.

30 patients with breast fibroadenomas accepted US guided percutaneous RFA and 30 patients with surgical excision under general or local anesthesia at Zagazig university hospital surgical department. The mean age was 18-65 years (35.44 \pm 13.50 years) for all 60 patients. The written consent was taken for accepting RFA and surgical excision for treating breast fibroadenomas before operation, patients informed by the risk of anesthesia and procedure complications.

\section{According to RF Patients selection used by the following criteria:}

All the patients met the following conditions:

1. Breast imaging by high frequency US examination;

2. All the patients did needle biopsy, and the pathological results indicated breast fibroadenoma.

3. The follow up time for all the patients was above 4 months to evaluate the degree of volume change of the ablated mass.

4. Most patients had multiple breast nodules.

5. All the patients ages above 18 years old.

6. The maximum diameter of the breast nodule was about $3 \mathrm{~cm}$ without any significant changes by follow up for more than one year.

7. No pregnant patient.

8. No lactating patient.

9. No severe concomitant diseases such as heart, brain, and liver diseases.

\section{Preoperative preparation and operation procedures of radiofrequency ablation}

1. FNAC, mammography and clinical examination done before any procedure to exclude the malignant changes.

2. All the patients examined by high frequency US before operation, to evaluate the location, the depth, the size, the shape, the internal echo of the lump, number of nodules, and the internal blood flow of the breast mass. The diameters of each nodule were measured, and the volumes $(\mathrm{mm} 3)$ were calculated using volume formula.

3. Two US system (Hitachi and Philips), L522 and L523, 7-10 MHz center.

4. RFA treatment system was radionic RF Generator with coon tip needle $15 \mathrm{~cm}$

5. All the operations were carried out in standard surgical operating room under general anesthesia.

\section{The steps of the procedure:}

The patients lie on supine position, with extended outside and fixed arms. RFA electrode was placed at the distal end of the nodular capsule under US guidance. The power was set up to 10-15W, with the center temperature up to 65$95^{\circ} \mathrm{C}$. The impedance of the ablation zone area slowly increased with more the degree of the ablation, and the RFA analyzer has automatic stop working once the impedance reached the highest degree, indicating complete ablation of the nodules. US monitoring was applied during the procedure, the location of the probe would be adjusted If the 
gasification range did not cover the tumor mass completely with one more ablation can be done until the gasification covers the whole tumor. For multiple tumors lump, they were ablated by the same way in the same sitting. Normal saline $0.9 \%$ or sterile water was injected between the skin and the nodule guided by US to make isolation zone to avoid local skin burns or necrosis. Local cold packs were applied for 5-6 hours after the operation to minimize the heat of the operation area. We make good homeostasis by compression. With review and follow up Time setting at 1 and 4 months after operation.

\section{Tumor ablation evaluation criteria by follow up:}

1. Complete ablation of the nodules: No enhancement seen by the US at all stages of the mass volume, showed as "black hole"

2. Partial ablation: US imaging show partial enhancement

3. No change: US imaging showed homogeneous enhancement, without significant lesion change compared to its preoperative state.

The volume reduction rate (VRR) was evaluated using the measurements of the lesion volume at 1 month and 4 months after operation.

\section{The characters of patients of surgically treated by excision:}

1. Family history of malignancy was considered

2. follow up after 3 years without regression

3. usually above 35 years old female

4. The size of mass usually above $2 \mathrm{~cm}$.

5. Clear edge, mobile and well circumscribed mass

6. FNAC, mammography and clinical examination done before any procedure to exclude the malignant changes.

\section{Results:-}

We had 30 cases with breast nodules with a total of 40 nodules. The maximum mean diameter of nodules was (5-30) mm.

\section{Size change of breast nodules after RF}

1. 1 month after ablation. The size was the maximum diameter of ablation lesion was $(5-19 \mathrm{~m})$.

2. 4 months after ablation, the maximum diameter of ablation lesion was $5-10 \mathrm{~mm}$ ). The size change of the tumors was significant.

3. Size change of breast nodules after surgical excisionBy circumaerolar cosmetic or sub mammary incision under local or general anesthesia the complete excision of the mass done Follow up after 6 months no any mass

\section{Complications}

After RF:

There was no significant skin burn or necrosis.

1. 2 cases had mild skin edema and inflammation that disappeared after 8 days.

2. No breast internal bleeding, no breast hematoma, and no definite infection or disfigurement.

3. There was no nipple discharge, no bleeding or cosmetic changes.

4. 10 cases suffered from pain for 4 days after the procedure that relived with ordinary analgesia.

5. Follow up 4 months still small residual mass $5 \mathrm{~mm}$.

\section{After surgical excision:}

There was no significant skin necrosis

1. 5 cases mild skin edema and inflammation after 4 days

2. 2 cases skin infection after 3 days with skin disfigurement after 2 months follow up

3. 1 case internal bleeding and hematoma treated by local drainage on bed after 48 hours

4. 20 patients suffered from pain 7 day after operation treated by analgesia

5. Follow up 6 months no any recurrent mass 


\section{Discussion:-}

Up to now, there is still considerable controversy about the time and the method of treatment for breast fibroadenomas. [10] Surgical resection was the only treatment procedure for breast fibroadenomas in the past who undergo giant invasive surgical resection to remove small and benign mass that do not danger.

The lives of patients. [11] the most common advice is follow up only by surgical resection under such conditions after observation especially with, (large tumor size and inability to rule out malignancy). [12] This concept of surgery has been reduced because the accidental harmful complication for patients with breast fibroadenoma by invasive surgery, In addition, the larger the tumor is the severity of injury and disfigurement caused by surgical resection will be, Therefore, RF has good therapeutic efficacy with minimally invasive procedure that does not affect the cosmetic appearance and function of the breast. [12] Endoscopic surgery had Transient complications included mild local subcutaneous emphysema and brachial palsy and hematoma and postoperative pain like mammotome duration. [13]

Clinical application of Mammotome (vacuum peeling) has more demands from patients with malignant breast mass. This technology was used first to identify the nature of the breast malignant mass [14] but slowly now is applied for benign breast mass and lump resection. [15]

Comparing to surgical resection, Mammotome only needs one or multiple $2.5-5 \mathrm{~mm}$ small incision, which leaves much less scarring than invasive classic surgery.

Also, if Compared with surgical resection, Mammotome has lower the incidence of complication at obvious degree, but the surgery is still cannot meet the patient's expectations due to high incidence of surgical field bleeding, or hematoma harmful damage of the surrounding tissues, and infection. However, comparing RFA, the 15 gauge puncture electrode of RFA, Mammotome is less cosmetic, longer postoperative pain like surgery. Post operative pain in 10 patients the pain persists 4 days but relived with ordinary analgesia but it was 10 days after surgical excision. Wang et al. [13] did a 6 month follow up after Mammotome procedure on breast fibroadenoma and found the tumor residual mass rate reached 3.4\% (positive residual). But by Thurley et al. [16] the recurrence rate of fibroadenoma was as high as $25-30 \%$. (Positive recurrence). This is due to the inability to clarify the edge of the nodular mass during the Mammotome. In contrast to our study there was no any residual mass or recurrence mass after 6 months after surgical excision. From our RF clinical data, there was no apparent skin scar or kelloid of the breast of all the patients, and there was no shape change of the breast; thus, RFA has some significant advantages of keeping the shape and skin integrity of the breast as well as for the esthetic effects with small residual mass recurrence but in surgical excision 3 cases had skin disfigurement. 2 cases after infection and one case after hematoma drainage. Some scholars reported that the ratio of the skin and surrounding muscle tissue burns caused by RFA was high, but in our study no significant skin or muscle burn resulted but only mild edema in 2 patients that disappeared 8 days later. No recurrence in surgical excision in our study observed.

\section{Conclusion:-}

RFA has its significant advantages in treating breast fibroadenoma, especially for multiple fibroadenomas. With proven effectiveness and high absorption rate ofAblated lesions without residual or recurrence rate but also mild edema to surrounding tissues which can maximally meet the esthetic demands of patients with insignificant recurrence. So, minimally invasive RFA techniques have great promise for effective, safe and cosmetic treatment of benign breast lesions with insignificance recurrence. The open surgery had significant postoperative pain and small disfigurement but without any recurrence rate.

\section{References:-}

1. Grady D. Study of breast biopsies finds surgery used too extensively. February 18, 2011. Available online: http://www.nytimes.com/2011/02/19/health/19cancer.html (Accessed: 1 Feb 2014).

2. Laufer MR, Goldstein DP. The breast: examination and lesions. In: Emans SJ, Laufer MR, Goldstein DP. eds. Pediatric \& Adolescent Gynecology. 5th ed. Philadelphia: Lippincott Williams \& Wilkins, 2005:729-59.

3. Smith BL. Fibroadenomas. In: Harris JR, Hellman S, Henderson IC, et al. eds. Breast diseases. 2nd ed. Philadelphia: Lippincott, 1991; 34-7.

4. Dixon JM, Dobie V, Lamb J, et al.Assessment of the acceptability of conservative management of fibroadenoma of the breast. Br J Surg 1996; 83:264-5 
5. Park CA, David LR, ArgentaLC.Breast asymmetry: presentation of a giant fibroadenoma. Breast J 2006; 12:451-61

6. Anderson BO, Masetti R, Silverstein MJ. Oncoplastic approaches to partial mastectomy: an overview of volume-displacement techniques. Lancet Oncol 2005; 6:145-57

7. Cochrane RA, Valasiadou P, Wilson AR, et al. Cosmesis and satisfaction after breast-conserving surgery correlates with the percentage of breast volume excised. Br J Surg 2003; 90:1505-9

8. Kompatscher P. Endoscopic capsulotomy of capsular contracture after breast augmentation: a very challenging therapeutic approach. PlastReconstrSurg 1992; 90:1125-6

9. Dowden RV, Anain S. Endoscopic implant evaluation and capsulotomy. PlastReconstrSurg 1993; 91:283-7

10. Colon GA, D'AmoreTF.Mammoscopy: the endoscopic intracapsular evaluation of mammary prostheses. PlastReconstrSurg 1993; 91:382-3

11. Eaves FF, 3rd, Bostwick J, 3rd, Nahai F, et al. Endoscopic techniques in aesthetic breast surgery. Augmentation, mastectomy, biopsy, capsulotomy, capsulorrhaphy, reduction, mastopexy, and reconstructive techniques. ClinPlastSurg 1995; 22:683-95

12. Kitamura K, Hashizume M, Sugimachi K, et al. Early experience of endoscopic extirpation of benign breast tumors via an extra-mammary incision. Am J Surg 1998; 176:235-8

13. Kitamura $\mathrm{K}$, Inoue $\mathrm{H}$, Ishida $\mathrm{M}$, et al. Endoscopic extirpation of benign breast tumors using an extramammary approach. Am J Surg 2001; 181:211-4

14. Lee EK, Kook SH, Park YL, et al.Endoscopy-assisted breast-conserving surgery for early breast cancer. World J Surg 2006; 30:957-64

15. Liu $\mathrm{H}$, Huang $\mathrm{CK}, \mathrm{Yu} \mathrm{PC}$, et al.Retromammary approach for endoscopic resection of benign breast lesions. World J Surg 2009; 33:2572-8

16. Cheng PJ, Vu LT, Cass DL, et al.Endoscopic specimen pouch technique for removal of giant fibroadenomas of the breast. J PediatrSurg 2012; 47:803-7

17. Shrotria S. Techniques for improving the cosmetic outcome of breast conservation surgery. Eur J SurgOncol 2001;27:109-12. 